\title{
MACC1 and HGF are associated with survival in patients with gastric cancer
}

\author{
GUOKAI DONG ${ }^{1}$, MAN WANG $^{2}$, GUANGFU GU ${ }^{2}$, SHANSHAN LI ${ }^{1}$, XIAOMING SUN ${ }^{1}$, \\ ZHOURU LI $^{1}$, HONGXING CAI ${ }^{1}$ and ZHENGQIU ZHU ${ }^{2}$ \\ ${ }^{1}$ Department of Forensic Medicine, Xuzhou Medical University; ${ }^{2}$ Department of Medical Oncology, \\ Affiliated Hospital of Xuzhou Medical University, Xuzhou, Jiangsu 221000, P.R. China
}

Received March 7, 2017; Accepted November 2, 2017

DOI: $10.3892 / \mathrm{ol} .2017 .7710$

\begin{abstract}
Metastasis-associsated in colon cancer 1 (MACC1), a newly identified oncogene, promotes tumor cell proliferation and invasion. In the present study, the expression of MACC1, hepatocyte growth factor (HGF) and its receptor, MET proto-oncogene (c-Met), was investigated in human gastric cancer tissues and adjacent normal tissues by immunohistochemistry. The association between the expression levels of the proteins and the clinicopathological parameters of the tumors were statistically analyzed. Furthermore, lentiviral particles expressing MACC1 were used to infect the hepatic satellite cell (HSC) line LX2. The expression of $\alpha$-smooth muscle actin (SMA), HGF, matrix metallopeptidase (MMP)-2 and MMP-9 in human HSCs was examined by western blotting and reverse transcription-quantitative polymerase chain reaction. Transwell assays were used to measure the effect of MACC1-infected or non-infected HSCs on the migration and invasion abilities of MKN45 and MKN74 gastric carcinoma cells in vitro. The results demonstrated that positive protein expression of MACC1, HGF and c-Met was significantly higher in human gastric cancer tissues compared with adjacent normal tissues. Positive expression of MACC1 and c-Met in gastric cancer tissues had no correlation with the sex, age, tumor location and peritoneal metastasis of patients, but was significantly correlated with tumor size, depth of tumor
\end{abstract}

Correspondence to: Professor Zhengqiu Zhu, Department of Medical Oncology, Affiliated Hospital of Xuzhou Medical University, 84 Western Huai-Hai Road, Xuzhou, Jiangsu 221000 , P.R. China

E-mail: js82880999@126.com

Professor Hongxing Cai, Department of Forensic Medicine, Xuzhou Medical University, 84 Western Huai-Hai Road, Xuzhou, Jiangsu 221000, P.R. China

E-mail: xzmccaihx@163.com

Key words: stomach neoplasms, metastasis-associated in colon cancer 1, hepatocyte growth factor, MET proto-oncogene, hepatic satellite cell, tumor cell invasion invasion, lymph node metastasis, TNM stage, histological differentiation, and overall (5 years) and disease-free survival (5 years). Positive expression of each MACC1, HGF and c-Met protein was demonstrated to be positively correlated with each other in human gastric cancer tissues. Western blotting results confirmed that MACC1 protein was overexpressed in MACC1-overexpressing lentivirus-infected HSCs. Overexpression of MACC1 significantly increased HGF, MMP-2, MMP-9 and $\alpha$-SMA expression levels in HSCs. Results from the Transwell assays indicated an increase in the number of MKN45 or MKN74 cells migrating towards MACC1-overexpressing HSCs, compared with control HSCs. These findings suggested that MACC1 may regulate the expression of HGF, MMP-2 and MMP-9 in HSCs, and may thus promote migration and invasion of gastric carcinoma cells. MACC1, HGF and c-Met might cooperatively participate in the malignant progression of gastric cancer. In conclusion, MACC1 might serve as a useful molecular target for the diagnosis, treatment and prognosis of gastric cancer.

\section{Introduction}

Despite a recent decline in the occurrence of gastric cancer worldwide, it remains one of the most common malignant tumors in China, and the second and third cause of morbidity and mortality in 2010, respectively (1). Great progress has been made in the treatment of gastric cancer; however, the survival rate in patients with gastric cancer remains low. Recently target-orientated therapies have become one of the hot topics in cancer-related research, but such studies on gastric cancer remain rare.

Distant organ metastasis is a sign of poor prognosis in patients with gastric cancer. Liver is a common target organ of gastric cancer metastasis (2). Hepatic stellate cells (HSCs) are a type of liver-specific mesenchymal cells. HSCs are postulated as a component of the prometastatic liver microenvironment; HSCs can be activated by tumor-derived factors to then promote the metastatic growth of tumor cells (3). A previous study has demonstrated that the expression of metastasis-associated in colon cancer 1 (MACC1) is significantly higher in activated HSCs (4). MACC1 is reported to be associated with distant metastasis in gastric cancer (5). MACC1 enhances migration, invasion and metastasis of cancer cells 
by activating the hepatocyte growth factor (HGF)/MET proto-oncogene (c-Met) signaling pathway (6). Overexpression of MACC1 increases invasion in cancer cells by enhancing epithelial-mesenchymal transition (EMT) (7), and is significantly correlated to decreased overall survival (OS) and disease-free survival (DFS) (8). These previous studies, therefore, suggest that MACC1 may have a significant role in promoting tumor metastases.

A previous study from our group has demonstrated that MACC1 is highly expressed in activated HSCs, and that MACC1 suppression decreased the expression of HGF/c-Met and the progress of EMT, which suggested that MACC1 may be involved in HSCs activation and promotion of metastatic growth. In the present study, expression of MACC1, HGF and c-Met were detected in both human gastric cancer tissues (GTs) and adjacent normal tissues (ATs) by immunohistochemistry (IHC), and then the relationship of protein expression for these three proteins and the clinicopathological parameters and clinical outcomes of the tumors were statistically analyzed. Furthermore, MACC1 overexpressing lentiviral vectors were used to infect HSCs, and to detect the effect of MACC1-overexpressing HSCs on the migration and invasion of gastric carcinoma cells.

\section{Materials and methods}

Patient tissue samples. Pathology-confirmed, primary gastric cancer tissue samples $(n=129)$ and their adjacent non-tumor tissues $(n=129)$ were acquired from patients whose tumors were removed thoroughly at the Affiliated Hospital of Xuzhou Medical University (Xuzhou, China) from January 2009 through December 2010. None of the patients received chemotherapy or radiotherapy prior to surgical resection and collection of samples. All the patients were successfully followed-up for 5 years. The Ethics Review Committee of Xuzhou Medical University (Xuzhou, China) approved this study, and informed consent was obtained from all patients.

IHC. Expression of MACC1, HGF and c-Met in GTs and ATs was detected by IHC. Specimens were fixed by $4 \%$ formaldehyde solution for a week at room temperature and embedded in paraffin and $4 \mu \mathrm{m}$ sections were prepared. Antigen recovery was performed by boiling the sections in citrate buffer $(\mathrm{pH}=6.0)$ for $2 \mathrm{~min}$ and subsequent cooling at room temperature (RT). To deactivate endogenous peroxidases, $3 \% \mathrm{H}_{2} \mathrm{O}_{2}$ was added. Goat serum (OriGene Technologies, Inc., Beijing, China) was used for blocking at RT for $15 \mathrm{~min}$. Antibodies (all from Abcam, Cambridge, MA, USA) targeting MACC1 (rabbit polyclonal; cat. no. ab106579; 1:500), HGF (rabbit polyclonal; cat. no. ab83760; 1:100) and c-Met (rabbit monoclonal; cat. no. ab51067; 1:250) were added to the sections and incubated at $4^{\circ} \mathrm{C}$ overnight. Histostain-Plus kit (OriGene Technologies, Inc.) was used for primary antibody detection, according to the manufacturer's instructions. Positive cells were visualized by 3,3'-diaminobenzidine staining. As a control, some sections were incubated with non-immune goat serum in place of the primary antibodies.

All the sections were observed by two experienced pathologists separately using Olympus CX31 (Olympus
Corporation, Tokyo, Japan). For conflict diagnosis, a third opinion was pursued. For each section, 10 non-contiguous optical fields (magnification, x400) were randomly captured, 100 cells from each field were observed for $\%$ calculation, and finally the mean of the 10 fields per section was acquired. The quantification criteria were as follows: i) Degree of staining: 0 points (negative staining), 1 point (yellow), 2 points (brown), 3 points (tan); ii) percentage of stained cells: 0 points (no positive cells), 1 point ( $\leq 10 \%), 2$ points (11-50\%), 3 points $(51-75 \%)$, 4 points $(>75 \%)$. If the product of these two scores was $>3$, it was considered as positive.

Cell lines and cell culture. The normal HSC line LX2 was donated by Jiangsu Key Laboratory of Immunity and Metabolism (Xuzhou, China). The human gastric cells lines MKN45 (poorly differentiated adenocarcinoma) and MKN74 (moderately differentiated adenocarcinoma) were donated by the Tumor Laboratory of Nanjing Medical University (Nanjing, China) and Shanghai Jiao Tong University (Shanghai, China), respectively. All cells were cultured in Dulbecco's modified Eagle's medium (DMEM; Gibco; Thermo Fisher Scientific, Inc., Waltham, MA, USA) supplemented with $10 \%$ mycoplasma-free fetal bovine serum (FBS; Gibco, Thermo Fisher Scientific, Inc.), penicillin $(100 \mathrm{U} / \mathrm{ml})$ and streptomycin $(100 \mu \mathrm{g} / \mathrm{ml})$, and incubated at $37^{\circ} \mathrm{C}$ in $5 \% \mathrm{CO}_{2}$.

Lentiviral infection. LX2 cells were seeded into 6-well plates and incubated at $37^{\circ} \mathrm{C}$ with $5 \% \mathrm{CO}_{2}$ overnight. The lentiviral vector overexpressing MACC1, LV5-MACC1, and its scrambled negative control, LV5-NC, were synthesized by GenePharma Co., Ltd. (Shanghai, China). LX2 cells were infected with $200 \mu \mathrm{l}\left(1 \times 10^{8} \mathrm{TU} / \mathrm{ml}\right)$ LV5-MACC1 or $100 \mu \mathrm{l}$ $\left(2 \times 10^{8} \mathrm{TU} / \mathrm{ml}\right) \mathrm{LV} 5-\mathrm{NC}$, according to the manufacturer's instructions.

Western blotting. For western blotting, cell lysates were prepared using radioimmunoprecipitation assay buffer and PMSF (1:100) (both from Beyotime Institute of Biotechnology, Shanghai, China). Protein concentrations were measured using the bicinchoninic acid assay (Beyotime Institute of Biotechnology), according to the manufacturer's instructions. Proteins (30 $\mu \mathrm{g} / \mathrm{lane})$ were separated with 10 or $7.5 \%$ SDS-PAGE and transferred to a nitrocellulose membrane. The membrane was blocked with 5\% skimmed milk for $2 \mathrm{~h}$ at room temperature, then incubated with primary antibodies against MACC1 (rabbit polyclonal; cat. no. ab106579; 1:2,000; Abcam), $\alpha$-smooth muscle actin (goat polyclonal; cat. no. ab21027; 1:1,000), HGF (rabbit polyclonal; cat. no. ab83760; 1:1,000) (both from Abcam), matrix metallopeptidase (MMP)-2 (rabbit polyclonal; cat. no. 4022S; 1:1,000), MMP-9 (rabbit polyclonal; cat. no. 3852S; 1:1,000) (both from Cell Signaling Technology, Inc., Danvers, MA, USA) and $\beta$-actin (mouse monoclonal; cat. no. TA-09; 1:4,000; ZSGB-Bio, Beijing, China) at $4^{\circ} \mathrm{C}$ overnight, followed by secondary antibody (goat anti-mouse, cat. no. 925-68020; goat anti-rabbit, cat. no. 925-68021; donkey anti-goat, cat. no. 926-68024; 1:10,000; LI-COR Biosciences, Lincoln, NE, USA) incubation for $2 \mathrm{~h}$ at room temperature. Results were detected using an Odyssey scanner (LI-COR Biosciences) 
Table I. Sequences of primers used for polymerase chain reaction analysis.

\begin{tabular}{|c|c|c|c|c|}
\hline Gene & GenBank ID & Primer & Sequence $\left(5^{\prime}-3^{\prime}\right)$ & Product size (bp) \\
\hline MACC1 & NM_182762.3 & $\begin{array}{l}\text { Forward } \\
\text { Reverse }\end{array}$ & $\begin{array}{l}\text { TGGACATTTTAGACGACACAGC } \\
\text { CCTCCTTGATGGTTTACTTTGC }\end{array}$ & 238 \\
\hline$\alpha-\mathrm{SMA}$ & NM_001100.3 & $\begin{array}{l}\text { Forward } \\
\text { Reverse }\end{array}$ & $\begin{array}{l}\text { ATGTGCGACGAAGACGAGAC } \\
\text { TTTCTGACCCATACCGACCA }\end{array}$ & 156 \\
\hline HGF & NM_000601.4 & $\begin{array}{l}\text { Forward } \\
\text { Reverse }\end{array}$ & $\begin{array}{l}\text { CGAGGGAAGGTGACTCTGAA } \\
\text { CACATCCACGACCAGGAAC }\end{array}$ & 154 \\
\hline MMP-2 & NM_004530.4 & $\begin{array}{l}\text { Forward } \\
\text { Reverse }\end{array}$ & $\begin{array}{l}\text { TATGGCTTCTGCCCTGAGAC } \\
\text { CACACCACATCTTTCCGTCA }\end{array}$ & 142 \\
\hline MMP-9 & NM_004994.2 & $\begin{array}{l}\text { Forward } \\
\text { Reverse }\end{array}$ & $\begin{array}{l}\text { AGTCCACCCTTGTGCTCTTC } \\
\text { ACTCTCCACGCATCTCTGC }\end{array}$ & 117 \\
\hline$\beta$-actin & NM_001101.3 & $\begin{array}{l}\text { Forward } \\
\text { Reverse }\end{array}$ & $\begin{array}{l}\text { CTTAGTTGCGTTACACCCTTTC } \\
\text { GTCACCTTCACCGTTCCAGT }\end{array}$ & 154 \\
\hline
\end{tabular}

MACC1, metastasis-associated in colon cancer 1; SMA, smooth muscle actin; HGF, hepatocyte growth factor; MMP, matrix metallopeptidase.

and were analyzed with ImageJ (1.6.024; National Institutes of Health, Bethesda, MD, USA).

RNA extraction and reverse transcription-quantitative polymerase chain reaction $(R T-q P C R)$. Total RNA was isolated using the Total RNA Extraction kit (Tiangen Biotech Co., Ltd., Beijing, China), according to the manufacturer's instructions. RNA concentration was determined by UV spectrophotometry, genomic DNA was removed and RNA was converted to cDNA using PrimeScript ${ }^{\mathrm{TM}}$ RT Reagent kit with gDNA Eraser (cat. no. RR047A; Takara Bio, Inc., Otsu, Japan). qPCR was performed using the SYBR ${ }^{\circledR}$ Premix Dimer Eraser (cat. no. RR091A; Takara Bio, Inc.) on a 7900HT Fast Real-Time PCR system (Thermo Fisher Scientific, Inc.). The PCR conditions were as follows: $95^{\circ} \mathrm{C}$ for $30 \mathrm{sec}$; 40 cycles at $95^{\circ} \mathrm{C}$ for $5 \mathrm{sec}$ and $55^{\circ} \mathrm{C}$ for $30 \mathrm{sec} 72^{\circ} \mathrm{C}$ for $34 \mathrm{sec}$; melt curve: $95^{\circ} \mathrm{C}$ for $15 \mathrm{sec}, 60^{\circ} \mathrm{C}$ for $1 \mathrm{~min}, 95^{\circ} \mathrm{C}$ for $15 \mathrm{sec}$. The sequence-specific primer pairs were synthesized by Sangon Biotech Co., Ltd. (Shanghai, China) and are listed in Table I. $\beta$-actin was used as an internal control. Relative quantification was calculated using the comparative threshold cycle $(\Delta \Delta \mathrm{Cq})$ method (9). To exclude any potential contamination, negative controls were also performed with $\mathrm{dH}_{2} \mathrm{O}$ instead of cDNA during each run. No amplification product was detected in the negative controls. qPCR reactions were run at least three times for each sample.

Cell invasion and migration assays. LX2 cells infected with LV5-MACC1 or LV5-NC were harvested following puromycin $(0.05 \mu \mathrm{g} / \mathrm{ml})$ selection. Gastric adenocarcinoma cell lines MKN45 and MKN74 were harvested for the cell invasion assays. For the invasion assays, 24-well $8.0 \mu \mathrm{m}$ pore Transwells (Corning Inc., Corning, NY, USA) coated with fibronectin (30 $\mu \mathrm{l} /$ well; BD Biosciences, Franklin Lakes, NJ, USA) were used, according to the manufacturer's instructions. MKN45 or MKN74 cells in serum-free DMEM (200 $\mu \mathrm{l}$ of a $1 \times 10^{5} / \mathrm{ml}$ cell suspension) were seeded in the upper chambers of the Transwells. HSCs infected with LV5-MACC1 or LV5-NC in $10 \% \mathrm{FBS} / \mathrm{DMEM}\left(600 \mu \mathrm{l}\right.$ of a $1 \times 10^{5} / \mathrm{ml}$ cell suspension) were seeded in the bottom chambers coated with Matrigel (25 $\mu \mathrm{l} /$ well; BD Biosciences). After $24 \mathrm{~h}$ of incubation, cells remaining on the top side of the membrane were removed with a cotton swab, while cells on the bottom side of the membrane were fixed in methanol and stained with $0.1 \%$ crystal violet (Sigma-Aldrich; Merck KGaA, Darmstadt, Germany). Invading cells were observed by Olympus CX31 and counted using Image J. For each section, 10 non-contiguous optical fields (magnification, x200) were randomly captured.

The migration assay was performed in the same manner as the invasion assay, but with uncoated Transwells and for a $12 \mathrm{~h}$ incubation period.

Statistical analysis. SPSS 19.0 (IBM Corp., Armonk, NY, USA) was used for all data analyses. The results were presented as the mean \pm standard deviation. Pearson, $\chi^{2}$ and Cox methods were used for analyzing the relationship between protein expression and clinicopathological parameters. One-way ANOVA with Student's t-test method for homogeneity of variance and Welch with Dunnett-t 3 method for missing variance were performed for analysis among groups. $\mathrm{P}<0.05$ was considered to indicate a statistically significant difference. All graphs were generated using GraphPad Prism 5.0 (GraphPad Software, Inc., La Jolla, CA, USA).

\section{Results}

MACCl and HGF expression are correlated with survival in gastric cancer patients. To investigate MACC1, HGF and c-Met expression in gastric cancer, IHC analysis was performed on matched tumor tissues (GTs) and adjacent normal tissues (ATs) from 129 patients with gastric cancer. Among these 129 cases, 89 were male and 40 were female. MACC1 was positively expressed in 104 GTs $(80.6 \%)$ and 41 ATs $(31.8 \%)$; HGF was positively expressed in 103 GTs (79.8\%) and 59 ATs 
Table II. Correlation analysis between positive expression of MACC1, HGF and c-Met and the clinicopathological parameters of gastric tumors.

\begin{tabular}{|c|c|c|c|c|c|c|c|c|c|c|}
\hline \multirow{2}{*}{$\begin{array}{l}\text { Clinicopathological } \\
\text { characteristics }\end{array}$} & \multirow[b]{2}{*}{ Patients, $\mathrm{n}$} & \multicolumn{2}{|c|}{$\begin{array}{l}\text { MACC1 } \\
\text { expression }\end{array}$} & \multirow[b]{2}{*}{ P-value } & \multicolumn{2}{|c|}{$\begin{array}{c}\text { HGF } \\
\text { expression }\end{array}$} & \multirow[b]{2}{*}{ P-value } & \multicolumn{2}{|c|}{$\begin{array}{c}\text { c-Met } \\
\text { expression }\end{array}$} & \multirow[b]{2}{*}{ P-value } \\
\hline & & - & + & & - & + & & - & + & \\
\hline Sex & & & & 0.071 & & & 0.328 & & & 0.677 \\
\hline Male & 89 & 21 & 68 & & 20 & 69 & & 16 & 73 & \\
\hline Female & 40 & 4 & 36 & & 6 & 34 & & 6 & 34 & \\
\hline Age, years & & & & 0.284 & & & 0.965 & & & 0.172 \\
\hline$<60$ & 65 & 15 & 50 & & 13 & 52 & & 14 & 51 & \\
\hline$\geq 60$ & 64 & 10 & 54 & & 13 & 51 & & 8 & 56 & \\
\hline Tumor size, $\mathrm{cm}$ & & & & 0.425 & & & 0.006 & & & 0.291 \\
\hline$<5$ & 63 & 14 & 49 & & 19 & 44 & & 13 & 50 & \\
\hline$\geq 5$ & 66 & 11 & 55 & & 7 & 59 & & 9 & 57 & \\
\hline Invasion depth & & & & 0.001 & & & $<0.001$ & & & $<0.001$ \\
\hline $\mathrm{T} 1+\mathrm{T} 2$ & 29 & 12 & 17 & & 14 & 15 & & 14 & 15 & \\
\hline $\mathrm{T} 3+\mathrm{T} 4$ & 100 & 13 & 87 & & 12 & 88 & & 8 & 92 & \\
\hline Lymph metastasis & & & & 0.144 & & & $<0.001$ & & & $<0.001$ \\
\hline- & 41 & 11 & 30 & & 16 & 25 & & 14 & 27 & \\
\hline+ & 88 & 14 & 74 & & 10 & 78 & & 8 & 80 & \\
\hline Periconeal metastasis & & & & 0.279 & & & 0.070 & & & 0.383 \\
\hline- & 113 & 24 & 89 & & 26 & 87 & & 21 & 92 & \\
\hline+ & 16 & 1 & 15 & & 0 & 16 & & 1 & 15 & \\
\hline TNM stage & & & & 0.009 & & & 0.001 & & & $<0.001$ \\
\hline $\mathrm{I}+\mathrm{II}$ & 48 & 15 & 33 & & 17 & 31 & & 17 & 31 & \\
\hline III+IV & 81 & 10 & 71 & & 9 & 72 & & 5 & 76 & \\
\hline Differentiation level & & & & 0.009 & & & 0.005 & & & 0.005 \\
\hline High & 53 & 16 & 37 & & 17 & 36 & & 15 & 38 & \\
\hline Low & 76 & 9 & 67 & & 9 & 67 & & 7 & 69 & \\
\hline Location & & & & 0.391 & & & 0.566 & & & 0.533 \\
\hline Cardia-fundus+gastric body & 51 & 8 & 43 & & 9 & 42 & & 10 & 41 & \\
\hline Antrum & 78 & 17 & 61 & & 17 & 61 & & 12 & 66 & \\
\hline OS, years & & & & 0.381 & & & 0.001 & & & 0.003 \\
\hline$<5$ & 72 & 12 & 60 & & 7 & 65 & & 6 & 66 & \\
\hline$\geq 5$ & 57 & 13 & 44 & & 19 & 38 & & 16 & 41 & \\
\hline DFS, years & & & & 0.292 & & & 0.000 & & & 0.002 \\
\hline$<5$ & 74 & 12 & 62 & & 7 & 67 & & 6 & 68 & \\
\hline$\geq 5$ & 55 & 13 & 42 & & 19 & 36 & & 16 & 39 & \\
\hline Expression & & & & $<0.001$ & & & $<0.001$ & & & $<0.001$ \\
\hline Tumor tissues & 129 & 25 & 104 & & 26 & 103 & & 22 & 107 & \\
\hline Adjacent normal tissues & 129 & 88 & 41 & & 70 & 59 & & 97 & 32 & \\
\hline
\end{tabular}

MACC1, metastasis-associated in colon cancer 1; HGF, hepatocyte growth factor; c-Met, MET proto-oncogene; OS, overall survival; DFS, disease-free survival.

(45.7\%); c-Met was positively expressed in 107 GTs $(82.9 \%)$ and 32 ATs $(24.8 \%)$. Overall, the number of MACC1, HGF or c-Met-positive patients was significantly higher in the GTs compared with the ATs $(\mathrm{P}<0.05$; Table II). In GTs, the number of MACC1-positive patients was significantly correlated with the number of HGF-positive patients $(r=0.182, \mathrm{P}=0.039)$ and the number of c-Met-positive patients $(r=0.508, \mathrm{P}<0.001)$. Similarly, the number of HGF-positive patients was significantly correlated with the number of c-Met-positive patients $(r=0.523, \mathrm{P}<0.001$; Fig. 1). The present results indicated that the expression levels of MACC1, HGF and c-Met are higher in gastric cancer tissues compared with adjacent normal tissues, 
and that they are significantly related to each other in gastric cancer.

Next, the relationship of positive expression for the MACC1, HGF and c-Met proteins and the various clinicopathological parameters of the gastric cancer patients were analyzed. The results of the statistical analysis are presented in Table II. Positive expression of MACC1 was significantly higher in $\mathrm{T} 3+\mathrm{T} 4$ GTs compared with $\mathrm{T} 1+\mathrm{T} 2$ GTs $(\mathrm{P}=0.001)$. Positive expression of MACC1 in III+IV grade GTs was significantly higher compared with grade I+II GTs $(\mathrm{P}=0.009)$. Positive expression of MACC1 was significantly higher in low differentiated GTs compared with well differentiated GTs $(\mathrm{P}=0.009)$. In addition, positive expression of $\mathrm{HGF}$ and $\mathrm{c}-\mathrm{Met}$ was significantly increased in GTs with T3+T4 stage, positive lymph node metastasis, III+IV grade, low differentiation status, and poor OS ( $<5$ years) and DFS ( $<5$ years), compared with GTs of T1+T2 stage, no lymph node metastasis, I+II grade, well-differentiated status, and good OS ( $>5$ years) and DSF ( $>5$ years), respectively (Table II). The present data indicated that high HGF and c-Met expression levels were associated with metastasis, life span, invasion depth, TNM stage and differentiation level; MACC1 expression levels were associated with invasion depth, TNM stage and differentiation level, but not significantly associated with metastasis and life span.

MACCl overexpression activates HSCs. The overexpression of MACC1 in lentivirally transfected cells was confirmed by western blotting (data not shown). To examine the effect of MACC1 on LX2 HSCs, the protein and mRNA expression levels of $\alpha$-SMA were detected. $\alpha$-SMA is a well-recognized marker of HSC activation (10). The results demonstrated that $\alpha$-SMA protein was expressed in LX2 HSCs (non-infected blank group) and in LV5-NC-infected HSCs (vector negative control group), but was significantly overexpressed in LV5-MACC1-infected HSCs (OE group); the mRNA expression levels of $\alpha$-SMA were also significantly higher in the OE group compared with the blank and vector groups $(\mathrm{P}<0.01$; Fig. 2). No significant difference was observed between the blank and the vector group ( $\mathrm{P}>0.05$; Fig. 2). The present data suggested that MACC1 stimulated the $\alpha$-SMA expression and thus activation of the LX2 HSCs.

MACC1 overexpression upregulates the levels of MMP-2 and MMP-9 in HSCs. MMP-2 and MMP-9 are involved in extracellular matrix (ECM) degradation and vascularization, processes that contribute to tumor metastasis. The results demonstrated that the mRNA and protein expression levels of MMP-2 and MMP-9 were significantly increased in the OE group compared with the blank and vector groups $(\mathrm{P}<0.01$; Fig. 2). No significant difference was observed between the blank and the vector group ( $>>0.05$; Fig. 2). These results indicated that MACC1 overexpression resulted in upregulated levels of MMP-2 and MMP-9 in LX2 HSCs.

MACCl overexpression increases the expression of $H G F$ in HSCs. The expression of HGF was detected in LX2 HSCs (blank), LV5-NC-infected HSCs (vector) and LV5-MACC1-infected HSCs (OE). The results demonstrated that the HGF protein expression levels were significantly
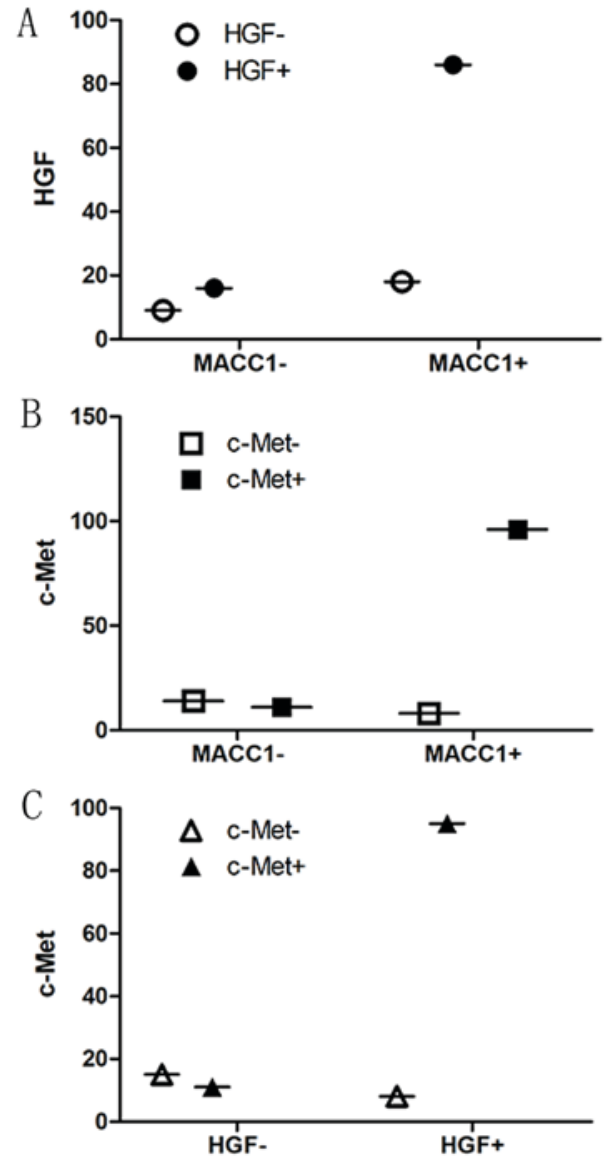

Figure 1. Analysis of the correlation between the number of MACC1, c-Met and HGF positive patients. (A) Mean number of MACC1 and HGF-positive patients; (B) mean number of MACC1 and c-Met-positive patients; and (C) mean number of c-Met and HGF-positive patients. MACC1, metastasis-associated in colon cancer 1 ; HGF, hepatocyte growth factor.

increased in the OE group compared with the blank and vector group $(\mathrm{P}<0.01$; Fig. 2$)$; similarly, the mRNA expression levels were also increased in the OE group compared with the blank and the vector group $(\mathrm{P}<0.05$; Fig. 2$)$. No significant difference was observed between the blank and the vector group ( $\mathrm{P}>0.05$; Fig. 2). The present data suggested that MACC1 overexpression results in increased HGF expression in LX2 HSCs.

MACC1 overexpression enhances migration and invasion in gastric cancer cells. To determine the effect of the activated HSCs on the invasion and migration potential of tumor cells, Transwell assays were performed. Migration and invasion assay results demonstrated that the number of MKN45 or MKN74 cells that crossed the membrane were significantly higher in the assays where the cells migrated towards the OE HSC group compared with the blank or vector groups $(\mathrm{P}<0.01$; Fig. 3). Of note, the number of MKN45 cells that crossed the membrane was significantly higher compared with that of MKN74 cells $(\mathrm{P}<0.01$; Fig. 3). No significant difference was observed between the blank group and the vector group ( $\mathrm{P}>0.05$; Fig. 3). The present data suggested that MACC1-overexpressing activated HSCs promoted migration and invasion of gastric tumor cells, with the effect being more prominent in poorly differentiated tumor cells. 

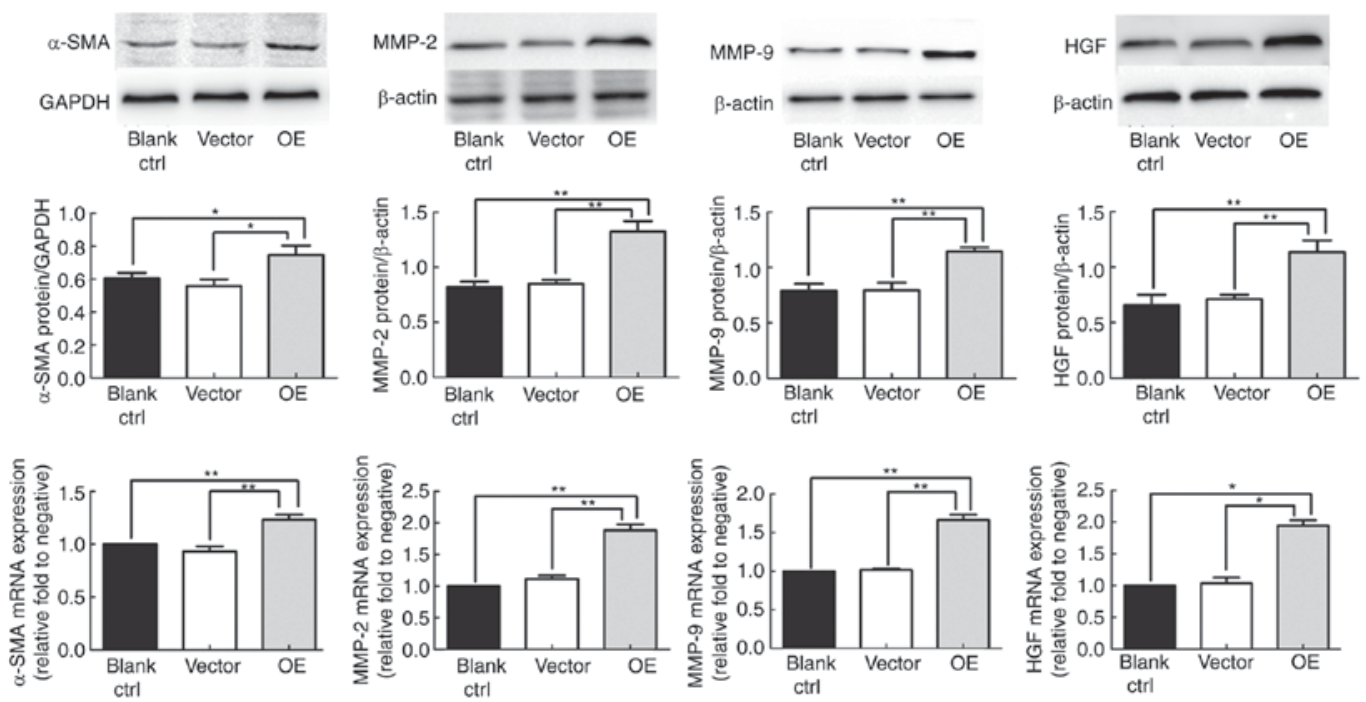

Figure 2. Protein and mRNA expression of $\alpha$-SMA, MMP-2, MMP-9 and HGF in HSCs. The protein and mRNA expression levels of $\alpha$-SMA, MMP-2, MMP-9 and HGF were significantly increased in the OE group compared with the blank and vector group. ${ }^{*} \mathrm{P}<0.05$ and ${ }^{* *} \mathrm{P}<0.01$, with comparisons indicated in brackets. SMA, smooth muscle actin; MMP, matrix metallopeptidase; HGF, hepatocyte growth factor; OE, overexpressor.

A

\begin{tabular}{cccc}
\hline Grow & Blank-Curl & Vector & OE \\
\hline MKN74 & $71.67 \pm 4.16$ & $77.67 \pm 3.51$ & $110.33 \pm 2.52^{* *}$
\end{tabular}

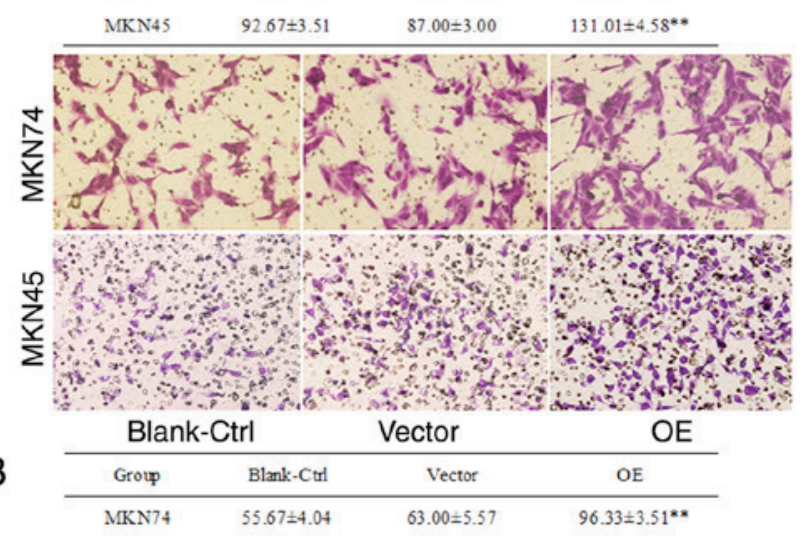

MKN45 $74.00 \pm 5.57 \quad 74.33=7.77 \quad 105 \pm 5.57 \%$

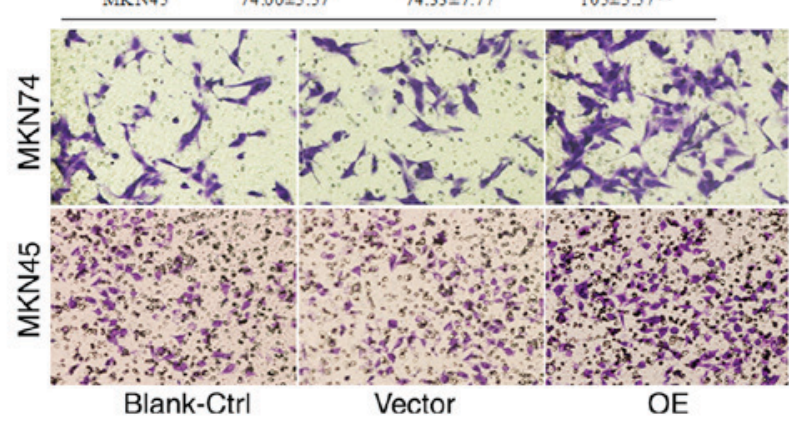

Figure 3. Migration and invasion assays of MKN45 or MKN74 cells (A) Migration and (B) invasion were measured using uncoated and coated transwell chambers, respectively. Representative images of the stained cells at the bottom of the Transwells are shown (magnification, x200). OE, overexpressor.

\section{Discussion}

MACC1 was first reported by Stein et al (11) as an oncogene regulating colon cancer metastasis, but MACC1 has been since reported to be highly expressed in several types of cancer cells $(12,13)$. The expression levels of MACC1 have been demonstrated to be significantly associated with peritoneal metastasis and TNM stage (14), as well as invasion depth and $\alpha$-fetoprotein levels (15). Therefore, MACC1 has been suggested as a potential biomarker for metastasis and invasion of colorectal cancer and primary hepatocellular carcinoma (16). High levels of MACC1 are also associated with lymph node metastasis and TNM stage in esophageal cancer, as well as a lower OS and a higher risk of death (17). The present study demonstrated that positive expression of MACC1 was significantly higher in GTs compared with ATs, and significantly correlated with invasion depth, TNM stage and differentiation status. These results implied that MACC1 might accelerate the progression and metastasis of gastric cancer and may serve as a new parameter for the prognostic prediction of gastric cancer.

Metastasis and recurrence are the main causes of death in patients with gastric cancer (5). Metastases to distant areas, resulting from primary gastric cancer, are localized mainly in the liver. $\alpha$-SMA-positive HSCs were described in human hepatocellular carcinoma and in liver metastases from primary gastric cancer (18). In the present study, first it was confirmed that MACC1 overexpression could activate HSCs, by upregulating $\alpha$-SMA expression. Activated HSCs displayed increased expression levels of MMP-2 and MMP-9, which are involved in ECM degradation and vascularization, allowing cancer cells to migrate out of the primary tumor and to form metastases (19). The present results are consistent with Chen et al (20), that reported that MACC1 downregulation inhibited $\alpha$-SMA, MMP-2, and MMP-9 mRNA or protein expression levels following transfection of endometrial carcinoma cells with MACC1 small interfering RNA. In addition, the present study used HSCs as a chemoattractant source for gastric cancer cells in Transwell assays. The results demonstrated that the number of MKN45 or MKN74 gastric cancer cells migrating through the membrane towards MACC1-overexpressing HSCs was significantly increased compared with non-activated HSCs. Furthermore, the number of migratory and invasive MKN45 cells was significantly higher than MKN74 cells. Consistent with the present results, knockdown of MACC1 has been 
reported to significantly suppress cell migration and invasion in melanoma cells (21). Thus, it is hypothesized that HSCs, activated by $\mathrm{MACC} 1$ overexpression, may promote migration and invasion of gastric cancer and this effect may be more pronounced in poorly differentiated cancer cells.

Further investigation may reveal the effects of MACC1 on HGF and c-Met expression. Both HGF and c-Met are associated with progression, metastasis and survival in gastric cancer (22). Previous studies have demonstrated that MACC1, similar with c-Met, is upregulated in hepatocellular carcinoma, and that the mRNA levels of MACC1 and c-Met are significantly associated (23). In the present study, analysis of gastric cancer clinical data demonstrated that positive expression of MACC1, HGF and c-Met was significantly higher in GTs compared with ATs. This result is consistent with a previous study (24). Expression of HGF was also detected in LX2 HSCs, LV5-NC-infected HSCs and LV5-MACC1-infected HSCs. The results demonstrated that both the protein and mRNA levels of HGF were increased in the MACC1-overexpressing cells. Therefore, this data suggested that MACC1 may increase the expression of HGF. Preclinical models have demonstrated that activation of MET signaling by HGF in gastric cancer cell lines promotes tumorigenesis and metastasis (25). Taken together, these results suggest that the effect of MACC1 on migration and invasion may occur through the $\mathrm{HGF} / \mathrm{c}-\mathrm{Met}$ signaling pathway.

In conclusion, the present investigation demonstrated that MACC1 and HGF expression were associated with survival in gastric cancer patients. MACC1 may promote the progression, metastasis and poor outcome of gastric cancer, through activation of the HGF/c-Met signaling pathway. Therefore, MACC1, HGF and c-Met may serve as potential cancer biomarkers in gastric cancer. Identification of inhibitors for the HGF/c-Met pathway might contribute to the therapy of gastric cancer. The present study might provide basic evidence for the diagnosis, therapy and prognosis assessment of gastric cancer, and may be helpful for the development of novel drug targets and biomarkers.

\section{Acknowledgements}

This study was supported by the Natural Science Fund Project of Colleges in Jiangsu (grant no. 16KJB340002), the Jiangsu Health Bureau Project (grant no. H201323), the Xuzhou Science and Technology Plan Project (grant no. KC15SM047), and the Xuzhou Medical University Scientific Research Fund for Talents (grant nos. D2016004 and D2016005).

\section{References}

1. Chen W, Zheng R, Zhang S, Zhao P, Zeng H and Zou X: Report of cancer incidence and mortality in China, 2010. Ann Transl Med 2: 61, 2014.

2. Fock KM: Review article: The epidemiology and prevention of gastric cancer. Aliment Pharmacol Ther 40: 250-260, 2014.

3. Mikuriya Y, Tashiro H, Kuroda S, Nambu J, Kobayashi T, Amano H, Tanaka Y and Ohdan H: Fatty liver creates a pro-metastatic microenvironment for hepatocellular carcinoma through activation of hepatic stellate cells. Int J Cancer 136: E3-E13, 2015.

4. Zhu Q, Shan H and Zhu Z: Regulation of epithelial-mesenchymal transition by MACC1 via the $\mathrm{HGF} / \mathrm{c}-$ Met signaling pathway and its effects on ability of migration and invasion of gastric carcinoma cells. J Shanghai Jiaotong Univ ( Med Sci) 34: 1325-1331, 2014.
5. Xie QP, Xiang C, Wang G, Lei KF and Wang Y: MACC1 upregulation promotes gastric cancer tumor cell metastasis and predicts a poor prognosis. J Zhejiang Univ Sci B 17: 361-366, 2016.

6. Stein U, Dahlmann M and Walther W: MACC1-more than metastasis? Facts and predictions about a novel gene. J Mol Med (Berl) 88: 11-18, 2010.

7. Wang L, Wu Y, Lin L, Liu P, Huang H, Liao W, Zheng D, Zuo Q, Sun L, Huang N, et al: Metastasis-associated in colon cancer-1 upregulation predicts a poor prognosis of gastric cancer, and promotes tumor cell proliferation and invasion. Int J Cancer 133: 1419-1430, 2013.

8. Wang G, Fu Z and Li D: MACC1 overexpression and survival in solid tumors: A meta-analysis. Tumour Biol 36: 1055-1065, 2015.

9. Navidshad B, Liang JB and Jahromi MF: Correlation coefficients between different methods of expressing bacterial quantification using real time PCR. Int J Mol Sci 13: 2119-2132, 2012.

10. Sobrevals L, Enguita M, Quiroga J, Prieto J and Fortes P: Insulin-like growth factor I (IGF-I) expressed from an AAV1 vector leads to a complete reversion of liver cirrhosis in rats. PLoS One 11: e0162955, 2016.

11. Stein U, Walther W, Arlt F, Schwabe H, Smith J, Fichtner I, Birchmeier W and Schlag PM: MACC1, a newly identified key regulator of HGF-MET signaling, predicts colon cancer metastasis. Nat Med 15: 59-67, 2009.

12. Ge Y, Meng X, Zhou Y, Zhang J and Ding Y: Positive MACC1 expression correlates with invasive behaviors and postoperative liver metastasis in colon cancer. Int J Clin Exp Med 8: 1094-1100, 2015.

13. Li H, Zhang H, Zhao S, Shi Y, Yao J, Zhang Y, Guo H and Liu X: Overexpression of MACC1 and the association with hepatocyte growth factor/c-Met in epithelial ovarian cancer. Oncol Lett 9: 1989-1996, 2015.

14. Shirahata A, Shinmura K, Kitamura Y, Sakuraba K, Yokomizo K, Goto T, Mizukami H, Saito M, Ishibashi K, Kigawa G, et al: MACC1 as a marker for advanced colorectal carcinoma. Anticancer Res 30: 2689-2692, 2010.

15. Shirahata A, Fan W, Sakuraba K, Yokomizo K, Goto T, Mizukami H, Saito M, Ishibashi K, Kigawa G, Nemoto H, et al: MACC 1 as a marker for vascular invasive hepatocellular carcinoma. Anticancer Res 31: 777-780, 2011.

16. Tang J, Chen JX, Chen L, Tang JY, Cui Z, Liu CH and Wang Z: Metastasis associated in colon cancer 1 (MACC1) promotes growth and metastasis processes of colon cancer cells. Eur Rev Med Pharmacol Sci 20: 2825-2834, 2016.

17. Zhu M, Xu Y, Mao X, Gao Y, Shao L and Yan F: Overexpression of metastasis-associated in colon cancer-1 associated with poor prognosis in patients with esophageal cancer. Pathol Oncol Res 19: 749-753, 2013.

18. Yanagihara K, Takigahira M, Kubo T, Ochiya T, Hamaguchi T and Matsumura Y: Marked antitumor effect of NK012, a SN-38-incorporating micelle formulation, in a newly developed mouse model of liver metastasis resulting from gastric cancer. Ther Deliv 5: 129-138, 2014.

19. Rink M, Chun FK, Robinson B, Sun M, Karakiewicz PI, Bensalah K, Fisch M, Scherr DS, Lee RK, Margulis V and Shariat SF: Tissue-based molecular markers for renal cell carcinoma. Minerva Urol Nefrol 63: 293-308, 2011.

20. Chen S, Zong ZH, Wu DD, Sun KX, Liu BL and Zhao Y: The role of metastasis-associated in colon cancer 1 (MACC1) in endometrial carcinoma tumorigenesis and progression. Mol Carcinog 56: 1361-1371, 2017.

21. Ding Y, Li X, Hong D, Jiang L, He Y and Fang H: Silence of MACC1 decreases cell migration and invasion in human malignant melanoma through inhibiting the EMT. Biosci Trends 10: 258-264, 2016.

22. Guo T, Yang J, Yao J, Zhang Y, Da M and Duan Y: Expression of MACC1 and c-Met in human gastric cancer and its clinical significance. Cancer Cell Int 13: 121, 2013.

23. Qiu J, Huang P, Liu Q, Hong J, Li B, Lu C, Wang L, Wang J and Yuan Y: Identification of MACC1 as a novel prognostic marker in hepatocellular carcinoma. J Transl Med 9: 166, 2011.

24. Wang L, Lin L, Chen X, Sun L, Liao Y, Huang N and Liao W: Metastasis-associated in colon cancer-1 promotes vasculogenic mimicry in gastric cancer by upregulating TWIST1/2. Oncotarget 6: 11492-11506, 2015.

25. Toiyama Y, Yasuda H, Saigusa S, Matushita K, Fujikawa H, Tanaka K, Mohri Y, Inoue Y, Goel A and Kusunoki M: Co-expression of hepatocyte growth factor and c-Met predicts peritoneal dissemination established by autocrine hepatocyte growth factor/c-Met signaling in gastric cancer. Int J Cancer 130: 2912-2921, 2012 